\section{La importancia de la salud bucal reflejada en la salud general de los pacientes pediátricos con trastornos sistémicos}

\author{
The relevance of the oral \\ health reflected in the general \\ health in the paediatric \\ patients with systemic \\ disorders
}

El concepto de salud de la Organización Mundial de la Salud, vigente desde hace varias décadas, refiere: "Estado de completo bienestar físico, mental y social y no solamente la ausencia de enfermedad"; por supuesto incluyendo a la salud bucal, reflejada de manera importante en el estado de salud general. Y no estamos hablando sólo de dientes sino de órganos dentarios, componentes de un sistema estomatognático (huesos, encías, nervios, vasos, músculos, mucosa, etcétera) con fisiología propia. En un estado patológico reflejan cambios significativos en la integridad física, mental y social del individuo considerado como aparentemente sano.

En lo que respecta al paciente con enfermedades sistémicas, la salud bucal adquiere una relevancia significativa para una recuperación mejor y más rápida y para que el tratamiento médico específico no se vea interrumpido por situaciones desencadenadas de un desequilibrio en la homeostasis bucal.
Un proceso patológico dentro de la cavidad bucal puede desencadenar afecciones sistémicas importantes como:

Focos infecciosos: la principal causa de interconsulta al Servicio de Estomatología de los pacientes sistémicamente comprometidos es la eliminación de focos infecciosos de la cavidad bucal. La boca es considerada como la cavidad más contaminada del cuerpo y con mayor cantidad y variedad de microorganismos (existen más de 200 variedades de bacterias aerobias y anaerobias en el cuerpo). De ahí la importancia de reducir el riesgo de una infección a distancia por patógenos orales. Por ejemplo, en el corazón recién operado no está bien definida la eficacia de la profilaxis antibiótica en la prevención de infecciones del corazón; sin embargo, está bien comprobado el valor del antibiótico en la disminución de la concentración de bacterias en el torrente sanguíneo. La American Heart Association tiene 
recomendaciones muy explicitas al respecto. Lockhart menciona que la profilaxis con antibióticos tiene más fundamentos de carácter médico legal que científico.

Desnutrición: las alteraciones estructurales y funcionales de la cavidad bucal son factores de riesgo que causan mala masticación que repercute como malnutrición en pacientes con enfermedades sistémicas; este es un problema que debe atenderse inmediatamente ya que un paciente bien nutrido enfrentará mejor los tratamientos médicos y quirúrgicos. De esta manera no se retrasaría la intervención quirúrgica por problemas alimentarios disminuyendo la morbilidad y la mortalidad asociadas con la malnutrición. Las alteraciones en el crecimiento son multifactoriales y entre esos factores se encuentra un aporte calórico disminuido asociado con el incremento de los requerimientos de energía producto, a su vez, de la afección subyacente.

Dolor: el dolor odontogénico es igual a todos los procesos álgicos: un mecanismo de defensa mediado por neurotransmisores como hidrogenasas, ATP, serotonina, noradrenalina, bradicinina, prostaglandinas y citocinas, entre otros, que alteran directa o indirectamente la función metabólica debido a que elevan la tensión arterial, las frecuencias respiratoria y cardiaca.

Fiebre y deshidratación: la fisiopatología de la fiebre desencadenada por procesos infecciosos crónicos en la cavidad bucal promueve la liberación de mediadores químicos, pirógenos endógenos como interleucinas 1 y 6 , factor de necrosis tumoral, interferón y proteína alfa que provocan una serie de efectos como: vasoconstricción, vasodilatación y secreción de adrenalina, entre otros, que se relacionan con la función cardiaca. La fiebre de origen dental produce deshidratación y altera el estado hemo- dinámico del paciente; en los cardiópatas causa pérdida de líquidos y electrólitos, fatiga, irritabilidad, letargo e hipernatremia que originan diarrea, sudoración, natriuresis e hipertonicidad muscular que, en casos muy severos, pueden ocasionar crisis convulsivas.

Autoestima: la percepción de uno mismo determina la actitud que se toma ante el mundo y sus problemas; en el paciente pediátrico la estética se relega debido a que los niños "no tienen un alto concepto de la vanidad"; sin embargo, la falta de órganos dentarios produce pérdida de la dimensión vertical del tercio medio e inferior de la cara, originando una "cara de viejo" que puede ser objeto de incomodidad en círculos sociales como escuela o familia y propiciar el acoso.

Asociado a todo esto existen tratamientos médicos (cirugías cardiacas, trasplantes, quimio- y radioterapia, tratamientos inmunodepresores, entre otros) que tendrán que ser suspendidos o pospuestos debido a focos infecciosos activos en la cavidad bucal y que ponen en riesgo la salud general del individuo.

Los tres niveles de prevención en un hospital de tercer nivel de atención

Según la Organización Mundial de la Salud cuando hablamos de prevención se trata de evitar la adquisición de la enfermedad, la detección precoz, el tratamiento oportuno y la rehabilitación; estos tres puntos se tornan fundamentales en la prevención de las afecciones bucales de los pacientes con enfermedades sistémicas. Prever la aparición de nuevas lesiones cariosas, limitar el daño mediante técnicas de restauración no traumáticas y la rehabilitación bucal propiamente dicha son cruciales para que nunca se suspenda un tratamiento médico por procesos infecciosos de la cavidad bucal. 
Prevención específica individualizada por factores de riesgo en los pacientes medicamente comprometidos

Generar un Programa de Prevención Específica Individualizada por Factores de Riesgo en Estomatología Pediátrica Hospitalaria (PPEIFRE$\mathrm{PH}^{\circledR}$ ) significa identificar los factores de riesgo y los datos de alarma en grupos de pacientes (homogéneos) de tercer nivel de atención y prevención en los tres niveles antes definidos y de forma inmediata; prevención determinada por factores de riesgo. Identificación y generación de centros capacitados de referencia y contrarreferencia de estos pacientes creando un modelo de atención replicable y sustentable para toda la población, con filosofía preventiva y bajo el conocimiento de que la salud bucal es parte integral e inamovible del concepto salud en general, responsabilidad de todos.

Un paciente portador de alguna enfermedad sistémica no está condicionado a desarrollar patología bucal especifica de su condición; sin embargo, si un paciente presenta afección bucal que debuta con enfermedad sistémica y no es rehabilitado de la boca tendrá un tratamiento y una recuperación con mayor complicación.
Un paciente que no lleva un programa específico de prevención y es portador de lesiones cariosas e infecciosas en la cavidad bucal puede condicionar su integridad física, Ilevarlo a ser subdiagnosticado e incluso a un desenlace fatal. Un ejemplo clásico es el paciente con fiebre inespecífica, de origen indeterminado y hospitalizado para encontrar la causa. Mientras lo estudian de manera fortuita es canalizado a estomatología porque "le duele un dientito"; al revisar la cavidad bucal se encuentran varios abscesos con dientes necróticos y restos radiculares: ahí está el "foco infeccioso inespecífico".

Al final, todo radica en la buena educación, para realizar buenas prácticas clínicas con un componente ético como piedra angular.

Dra. Rosaura Rosas-Vargas Directora de Enseñanza, INP Dr. Eduardo de la Teja-Ángeles Jefe del Servicio Estomatología Pediátrica-INP Lic. Marlene López-Ibarra Oral Care Business Manager 3M, Health Care Division Dr. Américo Durán-Gutiérrez Estomatólogo pediatra, profesor adjunto de la especialidad INP 